they should certify that they have done this. They should obtain a signature from the patient acknowledging that this has been explained to her and has been understood. This card should be filed with the $x$-ray or the diagnostic isotope request card. It should be pointed out that when there is a possibility of a hysterosapingography examination this should not be carried out within the first 7 days after the onset of a period and that it is essential that the patient should not become pregnant before the examination has been performed.

Proforma

STRICTLY CONFIDENTIAL

\section{$X$-RAY DIAGNOSIS} RECORD FORM FOR FEMALE PATIENTS
BETWEEN PUBERTY AND THE MENOPAUSE

To be completed by patient

Full Name

Date of birth

Date

The Code of Practice for the Protection of Person against Ionizing Radiation (1972) requires that the clinician requesting the examination should consider the possibility of an early pregnancy.

Will you please answer the following questions (1) Is there any possibility that you might be pregnant?

(Delete the word which is no

2) Please enter date of the 1st day

(3) I understand that it is important that I should avoid possible pregnancy until the $x$-ray exami booked for me has been carried out. I undertake to inform the staff of the $x$-ray department if there is any chance that I might have become pregnant.

Signature of patient

To be completed by the doctor:

Please indicate which of the alternative procedures you wish to be adopted.

(1) My patient $\mathrm{M} / \mathrm{s}$

has been asked to undergo an immediate $x$-ray examination. The questions relating to pregnancy OR

My patient $\mathrm{M} / \mathrm{s}$

is referred for a booked appointent. I have explained that she should not run a risk of preg-

\section{Signature of doctor}

This form should be completed when the clinician requests an $x$-ray examination of any part between
the diaphragm and the knees or a radioisotope investigation.

It is our view that the only way to cope with this problem is to place the onus on the patient to inform the doctor if there is any possibility of pregnancy and to take the necessary steps to see that she is not pregnant before being radiologically examined. It is clearly laid down in the code that it is the responsibility of the referring doctor to deal with this aspect. The $x$-ray department can then only do its best when this has been carried out. It is appreciated that this scheme might solve only about $95 \%$ of the problem, but this is probably the best that can be done. It is also appreciated that there may be difficulty with girls under the age of 16, but this should not deter us from attempting to deal with the main problem. It is suggested that a copy of Section 7 of the code should be sent to all medical practitioners with a covering letter, which might be based on the above.

Without the collaboration of referring physicians the problem, in our opinion, cannot be adequately solved and will inevitably result in delays and inefficiencies in any radiological service. We appreciate that whatever method is adopted would involve already overworked people in more work and we would invite suggestions as to how the problem may be adequately dealt with more conveniently or expeditiously. Of course i must be stressed that any pregnant women who, for good medical reasons, need to be radiographed should be radiographed carefully and the small hazard accepted as inevitable, as other hazards are accepted daily when necessary.-We are, etc.,

Radcliffe Infirmary, Oxford

G. M. ARDRAN F. H. KEMP

\section{Myeloid Leukaemia and Cot Deaths}

SIR,- - In view of the following observations it has occurred to me that myeloid leukaemia might be a numerically important cause of cot deaths.

(1) Acute leukaemias are notoriously difficult to recognize postmorten, and the earlier the death the greater the difficulty.

(2) Between the initiation of leukaemia and the onset of symptoms (incubation period) there is a prodigious increase in the risk of dying from respiratory infections.

(3) Before the second world war the number of acute lymphatic leukaemias which were mistaken for fatal pneumonias was far greate than the number of recognized cases. ${ }^{2}$

(4) The postwar increase in leukaemia mortality has not affected infants or older children with myeloid leukaemia, and it was much slower to affect chronic lymphatic leukaemiawhich is rarely diagnosed before 60 years of age-than other variants.

(5) During the first decade after the war there was a dramatic decrease in the infection death rate, and during the second decade there was an equally dramatic decrease in the number of deaths ascribed to senility, ${ }^{3}$ but there has been only a modest decrease in the number of stillbirths and neonatal deaths since 1945 .

(6) The vast majority of cancers which prove fatal before 10 years of age are initiated before the third trimester of fetal life.4

(7) The number of identical twins who die from cancers within 10 years of birth and have not been exposed to obstetric radiography is much smaller than the expected number. On the other hand, the number of twin-concordant cancers in this age range is far larger than the expected number. ${ }^{5}$

(8) Myelocytes have short cell generation times and are produced by a tissue which is relatively mature at birth. By contrast, circulating lymphocytes have long cell generation times and are produced by a tissue which is relatively immature at birth 6

(9) Intervals between diagnosis and death are shorter for acute myeloid than acute lymphatic leukaemias, but the difference is much smaller after the age of 10 years than before the age of 3 years

(10) Most of the acute lymphatic leukaemias which are caused by obstetric radiography are diagnosed between 3 and 6 years of age, but the corresponding set of myeloid leukaemias are concentrated between 7 and 10 years of age.

To an epidemiologist these miscellaneous observations suggest the following possibilities.

Early cancers have either germ cell or embryonic origins and when they cause blood dyscrasias instead of tumours they increase the risk of dying in utero, during parturition, and during childhood illnesses. Cancers have distinctive intervals between initiation and diagnosis which are related both to the nature and to the maturity status of the original "malignant" cell. Consequently myeloid leukaemia is a more acute disease than lymphatic leukaemia; embryomas are more acute diseases than adult cancers; and myeloid embryomas disappear from the scene earlier than lymphatic embryomas.

Myeloid embryomas are more often mistaken for other causes of death than lymphatic embryomas because the short incubation periods make them potent causes of stillbirths and infant deaths. They are also more often missed than other embryomas with equally short incubation periods because postmortem diagnosis of a blood dyscrasia poses more problems than postmortem diagnosis of a localized tumour.

If there were no difficulty in recognizing leukaemias after death we might find that myeloid embryomas produced a peak of mortality at birth-due to children who experienced a difficult delivery-and a second peak three to four months later due to children who had an easy birth followed by a cot death. ${ }^{8}$

If it were equally easy to recognize embryomas with short and long latent periods we might find that the early peak of leukaemia mortality at three years ${ }^{9}$ was as much an artefact as the late peak at 65 years. Nowadays the late peak is found only in societies which are supposed to be immune to chronic lymphatic leukaemia but are clearly living in conditions which make it easy to mistake this disease for the illdefined signs and symptoms of senility. ${ }^{310}$

On the assumption that we are recognizing only a quarter of the leukaemia deaths before 5 years, a haematology survey might find that the missing cases were responsible for $10 \%$ of unexplained stillbirths and a much higher proportion of cot deaths.-I am, etc.

Alice Stewart

Department of Social Medicine,

Oxford University

Kneale, G. W., British fournal of Preventive and Stewart, A. M., and Kneale, G. W., Nature, 1969, 223, 741 . S23, 741. M., in Clinics of Haematology, ed. S.
Roath, No. 1, p. 3. London, Philiadelphia, Saunders, 1972. Stewart 5 Data from Oxford Survey. Awaiting publication. Embryology, 4th edn. Cambridge, Heffer, 1972 . 7 Embryology, 4th edn. Cambridge, Heffer, 1972. of Medicine, 1972, 65, 245.

Unexpected, and Carpenter, R. G., Sudden and Unexpected Death in Infancy (Cot Deaths). Bristol, John Wright, 1972. Social D., British fournal of Preventive and 5 Segi, M, Kurihara, M., and Matsuyama, T. Cancer Mortality for Selected Sites in 24
Countries, (Nos. 1-5). Sendai, Japan, 1960-69.

\section{Erasures from the "Register"}

SIR,-We, the undersigned medical staff of the Middlesex Hospital Medical School, feel compelled to inform the General Medical Council of our profound disquiet at recent developments over the retention fee and the threat of imminent erasure hanging over many doctors who have witheld payment of the fee on grounds of principle until a public inquiry is held into the functions, structure, and financing of the General Medical Council.

There can be no doubt that the overwhelming majority of the profession would welcome such an inquiry, and Lord Cohen himself has declared publicly that he is not opposed to it. We urge the G.M.C. and the B.M.A. to take steps to ensure that this inquiry is held as soon as possible.

We must also totally deplore the threats of 